\title{
Differential Analysis of Psychopathological Impact of Cyberbullying in University Students
}

\author{
Elena Felipe-Castaño*, Benito León-del-Barco*, Mª Isabel Polo-del-Río, \\ Santiago Mendo-Lázaro, Teresa Gómez-Carroza and Fernando Fajardo-Bullón \\ Departamento de Psicología y Antropología, Facultad de Formación del Profesorado, University of Extremadura, \\ Cáceres, Spain
}

OPEN ACCESS

Edited by:

Eva M. Romera,

Universidad de Córdoba, Spain

Reviewed by:

Cristina Maria Coimbra Vieira, University of Coimbra, Portugal Annalisa Guarini,

University of Bologna, Italy

Natalio Extremera,

University of Málaga, Spain

*Correspondence:

Elena Felipe-Castaño efelipe@unex.es

Benito León-del-Barco bleon@unex.es

Specialty section:

This article was submitted to Educational Psychology,

a section of the journal

Frontiers in Psychology

Received: 21 February 2019 Accepted: 27 June 2019

Published: 17 July 2019

Citation:

Felipe-Castaño E

León-del-Barco B, Polo-del-Río Mal,

Mendo-Lázaro S, Gómez-Carroza T and Fajardo-Bullón F (2019)

Differential Analysis

of Psychopathological Impact

of Cyberbullying in University

Students. Front. Psychol. 10:1620.

doi: 10.3389/fpsyg.2019.01620
The new technologies (NT) and Internet are now a part of our lives and they are even changing the way in which we relate to each other, in both a positive and a negative sense, especially among young people. One of the negative aspects is their use to harass others, a phenomenon known as Cyberbullying. The aim of this study was to describe the frequency of cyberbullying, the characteristics of victims and aggressors in a sample of university students, and to analyze the relationships between the use of Internet and the presence of psychopathological symptomatology, as well as the differences in the psychopathological dimensions in relation to the intensity of the cyberbullying, cyberaggression and gender. The participants were 1108 university students selected using a randomized cluster sample. The results demonstrate the presence of cyberbullying in our participants. No differences were found with respect to gender in the frequency of being a victim; but differences were found in this respect in the case of the aggressors, as well as there being different symptomatology profiles in males and females and according to the intensity of the aggression. The results are discussed in relation to the differences according to gender, as well as the need to carry out longitudinal studies and to design prevention and intervention programs for university campuses that are sensitive to the differences between males and females.

Keywords: cyberbullying, cyberbullies, cybervictims, college students, psychopathological symptoms

\section{INTRODUCTION}

Cyberbullying is defined as intentional and recurrent aggression by a group or individual toward another individual, using electronic communication devices (Campbell, 2005; Smith et al., 2006).

Cyberbullying is considered to be a disguised form of verbal and written harassment (Mason, 2008), a characteristic it shares with traditional forms of harassment, but with some important differences, such as, for instance, that in cyberbullying there is nowhere you can be protected from it. In many cases, the harassment is public and may be observed indefinitely; the physical strength and size of the aggressor has no influence; the digital aggressor usually has good interpersonal relationships and cannot always be identified (Ybarra and Mitchell, 2004; Li, 2008; Ortega et al., 2008; Slonje and Smith, 2008; Heirman and Walrave, 2009).

Cyberbullying can be classified according to the means by which it is produced (Smith et al., 2006) and according to the type of harassment performed (Willard, 2006). Any kind of 
technological device and Internet can be used for this type of harassment: e-mail, mobile, social networks, instant messaging, and web pages. It must also be taken into account that, in cyberspace, the forms of harassment change and are reinvented as technological tools and resources develop.

The first studies on cyberbullying were published in the United States at the end of the last century and focused on the adolescent population (Finkelhor et al., 2000), since it was considered that adolescence was a time of particular risk due to the increase in the ease of access to new technologies (Tokunaga, 2010). Nevertheless, we are now seeing that cyberbullying continues into the university years and even later (Misawa, 2011). Research carried out on university students establishes different frequency percentages, with percentages of those involved in situations of cyberbullying being between 20 and $60 \%$, independently of the role assumed (Dilmac, 2009; MacDonald and Roberts-Pittman, 2010; Turan et al., 2011; Walker et al., 2011; Selkie et al., 2015). As for the differences with respect to gender there is no agreement concerning the victims: so, in the studies reviewed, it has been pointed out that there are no differences between male and female university students concerning cybervictimization (Balakrishnan, 2015); while others do find differences with respect to gender, pointing to a greater frequency of female victims and male aggressors in both adolescents (Li, 2006; Calvete et al., 2010) and university students (Dilmac, 2009; Schenk et al., 2013).

Interest in the study of the consequences of cyberbullying comes from research carried out into traditional school bullying. In general, people who suffer traumatic experiences or situations have different types of psychopathological symptomatology (van der Kolk, 2005; Briere et al., 2008). Traditional bullying at school sets off, in both victims and aggressors, clearly negative effects that make integration in the school environment and the normal development of learning more difficult, not to mention the negative consequences on physical and mental health, especially in the victims (Kumpulainen and Räsänen, 2000; Espelage and Holt, 2001; Ivarsson et al., 2005; Anderson and Hunter, 2012; Felipe-Castaño et al., 2013). In addition, there is a high probability that both the psychosocial maladjustment and the psychopathological symptomatology may last the rest of a person's life (Kumpulainen et al., 2001). Cyberbullying in adolescents has the same negative effects on mental health as traditional bullying (Wolak and Finkelhor, 2006; Hinduja and Patchin, 2007, 2010; Tokunaga, 2010), and could have an even greater impact on the victim (Slonje and Smith, 2008; Smith et al., 2008), as there is a higher correlation with suicidal behavior patterns and depression than traditional bullying (Bonanno and Hymel, 2013; van Geel et al., 2014).

University students involved as either victims or aggressors in situations of cyberbullying show an increase in depressive symptoms, alcohol consumption (Selkie et al., 2015) and a decrease in social skills (Kokkinos et al., 2014). Similar psychopathological profiles are to be found in aggressors and aggressors/victims, as well as an increase in anxiety and greater levels of distress in the students involved in comparison with those not involved (Schenk and Fremouw, 2012; Schenk et al., 2013).
Although more and more studies of cyberbullying in university students are becoming available, we believe it is necessary to continue acquiring more knowledge and better analyses of the characteristics and associated risk factors. Thus, the aim of this study was to describe the frequency of victims and aggressors involved in cyberbullying in a randomized sample of university students, and to analyze the relationship between the use of Internet and the Dimensions of the SA-45, as well as the differences in the psychopathological dimensions with respect to the intensity of the cyberbullying, cyberaggression and gender.

We will find differences between men and women regarding the experimentation of cyberbullying, so that women are more likely to be cyber-victims while men are cyber-aggressors. Then, the psychopathology associated with these profiles will be different for men and women. Men will present higher scores in dimensions related to externalizing symptoms such as hostility and psychoticism, while women will get higher scores in internalizing symptoms such as anxiety and depression.

\section{MATERIALS AND METHODS}

\section{Participants}

There were 1108 university students participating in the study, of whom 655 were female (59\%), between 18 and 41 years of age, with an average age of 20.95 ( $S D=3.43)$, students from all 4 years of undergraduate studies, belonging to 40 different degree subjects from 14 different Faculties in the public universities. The number of participants was determined on the basis of the number of students registered in the previous year, considering a sample error of $3 \%$ and a confidence interval of $95 \%$. A randomized cluster sampling was carried out using the Center or Faculty as the unit, while in each degree subject two class groups of students were randomly selected.

\section{Instruments}

\section{Sociodemographic Data and Information About the Use of Internet}

Questions referred to gender, age, year of studies, and Center or Faculty, whether they owned a computer and cell phone; How much time was spent dedicated to Internet in hours (daily and weekly), use and profiles in social networks.

\section{Scale of Victimization Through Internet (CYB-VIC, Buelga et al., 2012)}

This is made up of ten items with a Likert type response scale with four intervals ranging from 1 (never) to 4 (always). This scale measures whether the participants have suffered from bullying according to the modalities, proposed by Willard (2006), of harassment, persecution, vilification, identity theft and violation, invasion of privacy and social exclusion. The value of internal consistency obtained using Cronbach's $\alpha$ was 0.761 .

\section{Who Is the Aggressor?}

The participants were asked who they considered the aggressor to be. The options to answer were: companions from the faculty, persons from outside the faculty, persons met through Internet, 
ex-friends or ex-partners, acquaintances, but unsure whether it was them or not, or strangers.

\section{Duration}

This refers to how long the aggression lasted. The options for answering were: 1 month or less, from 3 to 6 months, and a year or more.

\section{Scale of Aggression Through Internet (CYB-AGRE, Buelga and Pons, 2012)}

This scale is made up of ten items that evaluate aggressions committed over the previous year through Internet according to the modalities proposed by Willard (2006). It uses a Likert type scale with five response options ranging from 1 (never) to 5 (many times). The value of the reliability coefficient obtained through Cronbach's $\alpha$ was 0.771 .

\section{Who Are Cyberaggressions Aimed at?}

This question referred to who the victim was. The options for answering were: companions of the faculty, persons from outside the faculty, persons met through Internet, ex-friends or ex-partners, and strangers.

\section{Duration}

This question referred to the time the aggression was maintained. The options for answering were: a month or less, from 3 to 6 months, and a year or more.

\section{SA-45 (Symptom Assessment-45 Questionnaire; Davison et al., 1997)}

We used the adaptation of Sandín et al. (2008). This version maintains the same psychometric characteristics as the original version. SA-45 is a revised version of the original SCL-90 (Symptom CheckList-90; Derogatis et al., 1973) that evaluates the degree of psychological unease experienced by a subject through 45 symptoms that make up nine symptomatic dimensions: Depression, Hostility, Somatization, Obsessioncompulsion, Interpersonal sensitivity, Anxiety, Phobic anxiety, Paranoid ideation and Psychoticism. The subject has to indicate how much each of the 45 symptoms has been present over the previous week, following a Likert type scale of five options for answering from 0 (not at all) to 4 (a lot or extremely). Internal consistency values were obtained from our participants, using the Cronbach's $\alpha$ value, of 0.94 for the total score of the scale and in each symptomatology dimension: Somatization $(\alpha=0.752)$, Obsession-compulsion $(\alpha=0.741)$, Interpersonal sensitivity $(\alpha=0.784)$, Depression $(\alpha=0.783)$, Anxiety $(\alpha=0.776)$, Hostility $(\alpha=0.752)$, Phobic anxiety $(\alpha=0.761)$, Paranoid ideation $(\alpha=0.711)$ and Psychoticism $(\alpha=0.701)$. This values were similar to original version.

\section{Procedure}

Once the class groups had been selected, the teachers of the selected courses were contacted to gain permission to carry out the data gathering among the students during class hours. Once the permission had been obtained, we personally informed the collaborating teachers of the aims of the study and attended the classrooms at the agreed times. Once in the classroom, the researchers informed the participants of the aims of the research and the fact that their participation was voluntary, as well as the anonymous and confidential nature of the data collected. Finally, we asked for the participants' informed consent in writing and asked them to respond sincerely to the questions.

Data collection was carried out over a 6 month period in the centers to which the students belonged, during class time and in the presence of the researchers. The time used to complete the questionnaires ranged from 30 to $40 \mathrm{~min}$. No incident occurred during data collection that could affect the research.

\section{Data Analysis}

The statistical package SPSS 20.0 for Windows was used to codify and analyze the data. To establish the different groups of intensity of cyberbullying, K-means clustering analyses were carried out. In order to analyze the differences of frequency between groups, contingency tables were created and we were using the Chi-square $\left(\chi^{2}\right)$ test. We were used Pearson's correlation to calculate the relationships between the variables. The analysis of the interaction between the intensity of the harassment and aggression and gender on the scores in the Dimensions of the SA-45 was carried out using a MANOVA, the value of the partial square $\left(\eta^{2}\right)$ was used as the size index of the effect. The calculation of the internal consistency of the scores in the Scales and Dimensions was performed using the value of Cronbach's $\alpha$.

\section{RESULTS}

\section{Use of Technological Devices and Internet}

The percentage of participants who had a computer was the 98.5\%, and $99 \%$ had a mobile phone, of whom $97 \%$ had access to Internet through the mobile phone. They dedicated between 0 and $17 \mathrm{~h}$, with an average of $31.32(S D=23.62)$ hours a week and $4.47 \mathrm{~h}$ a day $(S D=3.37)$, to surfing the net. Virtually all participants (98\%) had, at least, one profile in the social networks and of those $85 \%$ kept it up to date on a daily basis.

\section{Frequency of Cyber-Victimization and Cyber-Aggression, Duration and Persons Involved}

The percentage of participants who had indicated having suffered at least one situation of cyber-bullying was $77.6 \%$, while $51.2 \%$ stated they had committed at least one cyber-aggression over the previous year. As for the duration of the bullying, $19.5 \%(n=218)$ was for 1 month or less, $1.7 \%(n=19)$ between 3 and 9 months, and $0.9 \%(n=10)$ a year or more. While for the aggressors, $15.5 \%$ $(n=172)$ was for a month or less, $1.3 \%(n=14)$ between 3 and 9 months, and $0.9 \%(n=10)$ a year or more.

In order to analyze the frequency of cases according to the intensity of the cyberbullying and gender, groups (low, moderate and severe), according to the score on the CYB-VIC and CYBAGRE Scales (Table 1). To establish these groups we consider that the negative consequences of the victimization begin with 
TABLE 1 | CY-VIC and CY-AGRE group intensity by gender, frequency and percentage of participants, and descriptive statistics.

\begin{tabular}{|c|c|c|c|c|c|c|c|}
\hline & & & & \multicolumn{4}{|c|}{ Gender } \\
\hline & Group & \multicolumn{2}{|c|}{ Total } & \multicolumn{2}{|c|}{ Male } & \multicolumn{2}{|c|}{ Female } \\
\hline \multirow[t]{2}{*}{ CY-VIC } & $\mathrm{L}$ & $616(56)$ & $10.88(0.83)$ & 267 (58.9) & $10.78(0.81)$ & 349 (53.3) & $10.97(0.83)$ \\
\hline & M & $452(41)$ & $14.39(1.44)$ & $168(37.1)$ & $14.52(1.53)$ & $284(43.4)$ & $14.31(1.38)$ \\
\hline & M & 390 (35) & $13.80(2.24)$ & $181(40)$ & $14.34(2.60)$ & 209 (31.9) & $13.32(1.75)$ \\
\hline & $S$ & $9(1)$ & $33.11(7.88)$ & 7 (1.5) & $34.29(8.67)$ & $2(0.3)$ & $29(1.41)$ \\
\hline
\end{tabular}

L: Low; M: Moderate; S: Severe.

TABLE 2 | Frequency and percentage of participants: who harasses and who is harassed by gender - Chi-square $\left(x^{2}\right)$ test.

\begin{tabular}{|c|c|c|c|c|c|c|}
\hline & \multicolumn{3}{|c|}{ Cyber-victims } & \multicolumn{3}{|c|}{ Cyber-bullies } \\
\hline & Male & Female & $\chi^{2}$ & Male & Female & $x^{2}$ \\
\hline Faculty friends & $13(2.9)$ & $16(2.4)$ & 0.186 & $38(8.4)$ & $21(3.2)$ & $14.266^{* *}$ \\
\hline Persons outside the faculty & $39(8.6)$ & $52(7.9)$ & 0.151 & $78(17.2)$ & $63(9.6)$ & $13.928^{* *}$ \\
\hline Unknown persons & $19(4.2)$ & $28(4.3)$ & 0.005 & $12(2.5)$ & $19(2.8)$ & 0.03 \\
\hline Total & 147 (32.5) & 247 (37.6) & & 174 (38.2) & $193(29.2)$ & \\
\hline
\end{tabular}

${ }^{* *} p<0.001 ; * p<0.05$

a frequency of occurrence two to three times a month (Soldberg and Olweus, 2003). We found statistically significant differences in the frequency of aggressors, in the sense that there were more males in the moderate and severe groups of aggressors, while we also found more females in the low intensity aggression group $\left(\chi^{2}(2)=16.04 ; p<0.000\right)$.

As for who carries out the harassment (Table 2), we find statistically significant differences in that women said they were harassed more frequently by ex-friends or ex-partners $\left(\chi^{2}(1)=5.24 ; p=0.022\right)$, while men said they more frequently harassed faculty friends $\left(\chi^{2}(1)=14.26 ; p<0.000\right)$ and persons outside the faculty $\left(\chi^{2}(1)=13.92 ; p<0.000\right)$. It should be pointed out that $24.8 \%(n=139)$ of the victims and $10.3 \%(n=59)$ of the aggressors did not know who was harassing them or who they were harassing, or they were not sure.

\section{Time Dedicated to Internet, CYB-VIC, CYBAGRESS and Score in the SA-45 Dimensions}

The correlation coefficients were calculated between the scores in the SA-45 Dimensions and the hours dedicated to Internet per day by gender. We found direct and statistically significant correlations in males, although they were of low intensity, between the hours dedicated to surfing the net and all the SA-45 Dimensions, in the following order from greater to lesser intensity: Interpersonal sensitivity $(r=0.164 ; p<0.001)$;
Psychoticism $(r=0.141 ; p<0.01)$; Phobic anxiety $(r=0.138$; $p<0.01)$; Depression $(r=0.113$; $p<0.01)$; Hostility $(r=0.109$; $p<0.01)$; Paranoid Ideation $(r=0.102 ; p<0.01)$ and Somatization, Anxiety and Obsession-compulsion $(r=0.100$; $p<0.01)$. We found direct statistically significant correlations between the dimensions of the SA-45 and the score in CYB-VIC and CYB-AGRESS, both male and female (see Table 3 ).

\section{Intensity of Cyberbullying and Cyberaggression by Gender}

An analysis of the variance of the factors (MANOVA) was calculated in order to analyze the interaction between gender and intensity of the cyber-victim and cyber-aggressor on the scores in the SA-45 Dimensions and we found that the interaction was significant for the gender and cyber-victim groups (Wilks $\lambda=0.954 ; F=2.89, p<0.000, \eta^{2}=0.023$ ), in the sense that the observed differences in the SA-45 Dimensions between males and females are not the same in all the cyber-victim groups. To be precise, we found statistically significant differences in the dimensions of Hostility $(F=4.670$; $\left.p=0.010 ; \eta^{2}=0.008\right)$, Anxiety $\left(F=6.769 ; p=0.001 ; \eta^{2}=0.012\right)$ and Psychoticism $\left(F=6.964 ; p=0.001 ; \eta^{2}=0.013\right)$, in the sense that the males obtained higher scores than the females in the dimensions of Anxiety of the severe victimization group and Psychoticism and Hostility in the severe and moderate victimization groups; while the females obtained higher scores 
TABLE 3 | Correlation analysis.

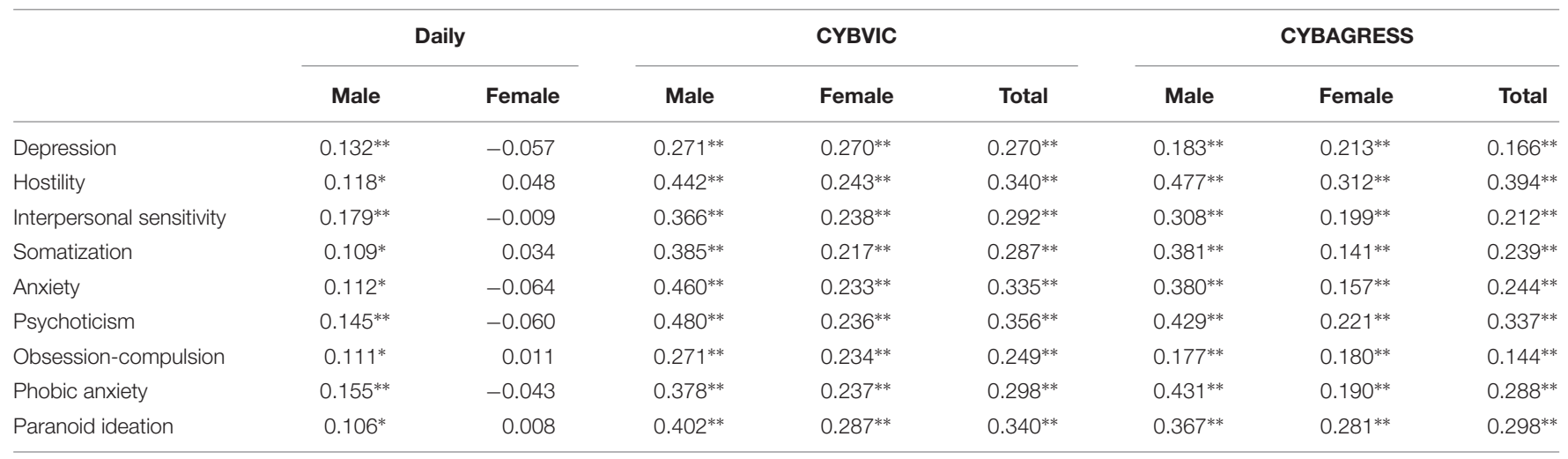

SA-45 Dimensions and daily hours dedicated to surfing the Internet, and CYBVIC and CYBAGRESS by gender. ${ }^{* *} p<0.001 ;{ }^{*} p<0.05$. CYB-VIC: Scale of victimization through Internet; CYB-AGRES.

TABLE 4 | Mean and standard deviation: contrasts according to gender by cybervictim group.

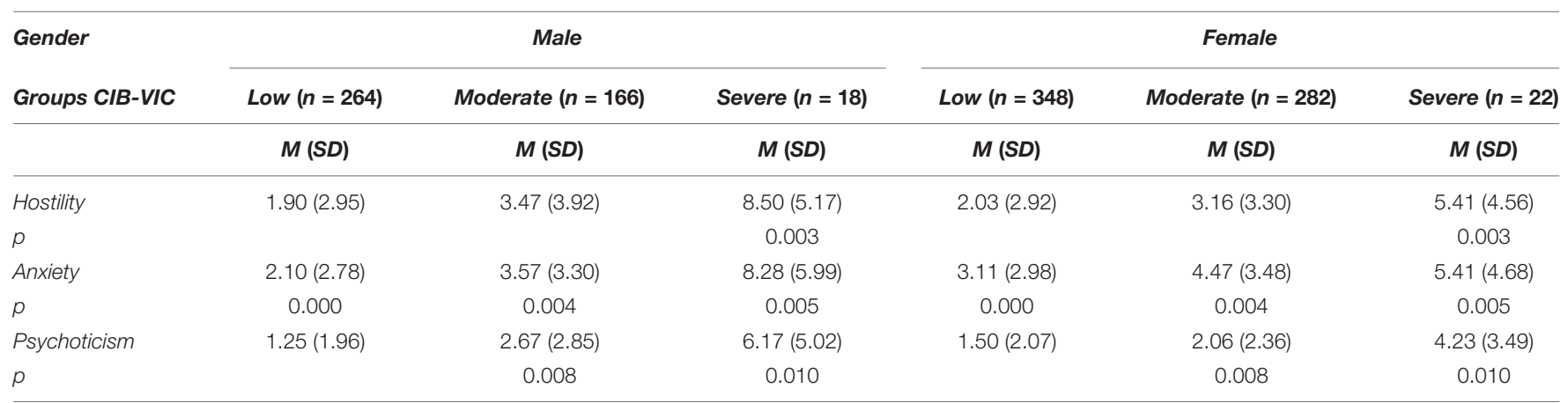

CIB-VIC: Scale of victimization through Internet.

in comparison to males in the dimension of Anxiety in the low and moderate victimization groups (Table 4). Males who described themselves as victims of cyberbullying obtained significantly higher scores than the females in Anxiety, Hostility and Psychoticism, which are conceived as clinical manifestations of anxiety and general signs of emotional tension and their psychosomatic manifestations, together with thoughts, feelings and behavior patterns characteristic in states of aggressiveness, anger and irritability as well as feelings of social alienation and isolation, with interpersonal difficulties.

\section{DISCUSSION}

The aim of this study was to describe the frequency and characteristics of cybervictims and cyberaggressors in a random sample of university students, and to analyze the relationships between the use of Internet and the SA-45 Dimensions, as well as the differences in the psychopathological Dimensions according to the intensity of the cyberbullying and cyberaggression and gender.

Practically all the participants had cell phones with access to Internet and used them daily, having at least one active profile in the social networks. Access to and use of Internet has become widespread since the appearance of smartphones, which allow rapid access similar to that of a PC.
The results show high percentages of cybervictims and cyberaggressors, but percentages which are lower than those found for university students in other countries (Dilmac, 2009; Turan et al., 2011; Selkie et al., 2015). The social and cultural characteristics of the different countries could explain these differences, as well as the use of different data gathering instruments based on different definitions of cyberbullying. We can conclude that cyberbullying takes place at all educational levels and is quickly becoming a social problem (Misawa, 2010) due, among other things, to the rapid development of the technological tools and the population's quick and easy access.

As for differences regarding gender in the question of being victim or aggressor, our results coincide with those obtained by other researchers who find a greater frequency of male aggressors (Li, 2006; Smith et al., 2008; Dilmac, 2009; Calvete et al., 2010), but not with respect to the victims, since no differences were found between males and females, a result similar to that obtained by Balakrishnan (2015). It would be necessary to continue investigating, since much of the research work was carried out with samples of adolescents, while our results were obtained from university students, who are older and have different social characteristics.

As for the identity of the aggressor, a significant percentage of female participants were harassed by ex-friends or ex-partners. The break-up of interpersonal relationships, especially those of 
friendship or partners, could be another factor associated with the presence of cyberbullying, in addition to jealousy, envy and racial and sexual intolerance (Hoff and Mitchell, 2009). This fact connects directly with aspects related to gender violence in so far as the ICTs are used as another tool with which to continue the aggressions. We believe this aspect should be dealt with in particular through the need to control the behavior patterns of cyberbullying. It is also important to stress the fact that, in many cases, the aggressor cannot be identified, which means that the victim feels defenseless against the attacks and therefore the consequences can be even more devastating (Li, 2008; Heirman and Walrave, 2009).

Among males, we find a significant relation between the hours dedicated to surfing the net and the scores in the SA-45 Dimensions, but not so with females. In addition, we find different psychopathological profiles in men and women who describe themselves as victims. This result demonstrates that being a victim of cyberbullying is related with a different symptomatology in men and women. Male victims are characterized by greater anxiety, hostility and psychoticism. We should note the presence of anxiety, a psychopathological symptom in which women usually obtain higher scores than men (Derogatis, 2002; Sandín et al., 2008).

It still remains to be seen whether the presence of psychopathological symptoms are the cause or the consequence of the situations of harassment (Menesini et al., 2009). We also believe, however, that it would be necessary to investigate these results in greater depth through the design of longitudinal studies that would allow the behavioral and psychopathological antecedents to be established, as well as the consequences that these experiences may have on a person's mental and physical health.

We consider it necessary to always analyze cyberbullying from the perspective of differences according to gender, as both the role played (where the aggressors are more often male) and the associated psychopathological correlations are different in men and women. Knowledge of the differential psychopathological profiles will be useful when it comes to designing prevention and intervention programs sensitive to the differences, as well as for the formulation of explanatory hypotheses concerning cyberbullying.

It can be concluded that generalized access to the ICTs by our adolescents and young adults is modifying the styles of interaction and interpersonal relationships. Face to face relationships are not the same as when one is not sure who the other person is or whether that person is really who they say they are. In our society, we depend to an ever greater extent on technological tools for studying, for social relationships and leisure; in fact, universities facilitate and recommend access to Internet and social networks as another tool in a person's formation. Making a good use of these tools and being able to detect when there is inadequate behavior, as well as what to do in such circumstances, is essential for the protection of our students. It is, therefore, ever more necessary to implement prevention programs at all educational levels, especially in university, as this is a stage when access to Internet and social networks is especially facilitated, if not actually required, by the institution itself. We therefore agree with the proposal of Washington (2014) with respect to the idea that universities should develop informative programs and prevention and intervention procedures that will guarantee security, in the widest sense of the word, on campuses. In view of our results, we consider that psychotherapy interventions aimed at preventing cyberbullying in university context may best focus on specific pattern in males and females and specific levels of intensity of cyberbullying.

\section{LIMITATIONS}

The study we have carried out has several limitations to the scope of the conclusions. This study was cross-sectional and therefore the relationship between variables cannot be examined theoretical, so the use of self-reporting in the information gathering, which may affect the honesty of the responses and the social desirability. Future work should have other instruments for data collection that can help to contrast the results, such as individual interviews or self-registration, and should use more sophisticated analysis to examine potential prediction the role of SA-45 Dimensions on use of Internet. Participants were, a priory, healthy and that the findings may not generalize to victims of cyberbullying diagnosed with post-traumatic stress disorder and belong to a group with very homogeneous educational and sociodemographic characteristics; it would therefore be necessary to complement this with other groups of nonuniversity participants of the same age and with different social and demographic characteristics, as well as a different access and use profile. For these reasons, the results cannot be generalized to other population groups.

\section{DATA AVAILABILITY}

All datasets generated for this study are included in the manuscript and/or the supplementary files.

\section{ETHICS STATEMENT}

As for ethical norms, the study received approval from the Ethics Committee of the University of Extremadura. Prior to administering the questionnaire, following the ethical directives of the American Psychological Association (2009), the students gave their informed consent to participate in the research, guaranteeing the anonymity and confidentiality of the data and their exclusive use for research purposes.

\section{AUTHOR CONTRIBUTIONS}

EF-C and BL-d-B analyzed and interpreted the data. EF-C, M-IP-d-R, and SM-L drafted the work. EF-C, BL-d-B, M-IP-d-R, TG-C, and FF-B conceived and designed the work. 


\section{REFERENCES}

Anderson, S., and Hunter, S. C. (2012). Cognitive appraisals, emotional reactions, and their associations with three forms of peer-victimation. Psicothema 24, 621-627.

Balakrishnan, V. (2015). Cyberbullying among young adults in Malaysia. The roles of gender, age and internet frequency. Comput. Hum. Behav. 46, 149-157. doi: $10.1016 /$ j.chb.2015.01.021

Bonanno, R. A., and Hymel, S. (2013). Cyber bullying and internalizing difficulties: above and beyond the impact of traditional forms of bullying. J. Youth Adolesc. 42, 685-697. doi: 10.1007/s10964-013-9937-1

Briere, J., Kaltman, S., and Green, B. L. (2008). Accumulated childhood trauma and symptom complexity. J. Trauma Stress 21, 223-226. doi: 10.1002/jts.20317

Buelga, S., Cava, M. J., and Musitu, G. (2012). Validación de la Escala de Victimización entre Adolescentes a través del Teléfono Móvil y de Internet [Validation of the adolescent victimization through mobile phone and the internet scale]. Rev. Panam. Salud Pública 32, 36-42. doi: 10.1590/s102049892012000700006

Buelga, S., and Pons, J. (2012). Agresiones entre adolescentes a través del teléfono móvil y de Internet [Aggressions among adolescents through mobile phones and the internet]. Psychosoc. Interv. 21, 91-101. doi: 10.5093/in2012v21n1a2

Calvete, E., Orue, I., Estévez, A., Villardón, L., and Padilla, P. (2010). Cyberbullying in adolescents: modalities and aggressors' profile. Comput. Hum. Behav. 26, 1128-1135. doi: 10.1016/j.chb.2010.03.017

Campbell, M. A. (2005). Cyberbullying: an old problem in a new guise? Aust. J. Guid. Counc. 15, 68-76. doi: 10.1375/ajgc.15.1.68

Davison, M. K., Bershadsky, B., Bieber, J., Silversmith, D., Maruish, M. E., and Kane, R. L. (1997). Development of a brief, multidimensional, self-report instrument for treatment outcomes assessment in psychiatric settings: preliminary findings. Assessment 4, 259-276. doi: 10.1177/107319119700400306

Derogatis, L. R. (2002). SCL-90-R. Cuestionario de 90 síntomas. Manual [SCL90R. SymptomCheckList-90-Revised. Mannual]. Madrid: TEA Ediciones.

Derogatis, L. R., Lipman, R. S., and Covi, L. (1973). SCL-90: an outpatient psychiatric rating scale-preliminary report. Psychopharmacol. Bull. 9, 13-27.

Dilmac, B. (2009). Psychological needs as a predictor of cyber bullying: a preliminary report on college students. Educ. Sci. Theory Pract. 9, 1307-1325.

Espelage, D. L., and Holt, M. K. (2001). "Bullying and victimation during early adolescence. Peer influences and psychosocial correlates," in Bullying Behavior: Current Issues, Research and Interventions, eds R. A. Geffner, M. Loring, and C. Young (New York, NY: Haworth), 123-142. doi: 10.1300/j135v02n02_08

Felipe-Castaño, E., León, B., and Fajardo, F. (2013). Perfiles psicopatológicos en participantes en situaciones de bullying en Educación secundaria [Psychopathological profiles in participants in situations of bullying in Secondary Education]. Behav. Psychol. 21, 475-490.

Finkelhor, D., Mitchell, K. J., and Wolak, J. (2000). Online Victimization: A Report on the Nation's Youth. Alexandria, VA: National Center for Missing and Exploited Children.

Heirman, W., and Walrave, M. (2009). Asseing issues and concerns about the mediation of technology in cyberbullying. Trípodos Extra 1, 317-329.

Hinduja, S., and Patchin, J. W. (2007). Offline consequences of online victimation, school violence and delinquency. J. Sch. Violence 6, 89-112. doi: 10.1300/ j202v06n03_06

Hinduja, S., and Patchin, J. W. (2010). Bullying, cyberbullying, and suicide. Arch. Suicide Res. 14, 206-221. doi: 10.1080/13811118.2010.494133

Hoff, D. L., and Mitchell, S. N. (2009). Cyberbullying: causes, effects, and remedies. J. Educ. Admin. 47, 652-665. doi: 10.1080/13811118.2010.494133

Ivarsson, T., Broberg, A. G., Arridsson, T., and Gillberg, C. (2005). Bullying in adolescence: psychiatric problems in victims and bullyies as measured by the youth self report (YSR) and de Depression self-rating scale (DSRS). Norwegian J. Psychiatry 59, 365-373. doi: 10.1080/08039480500227816

Kokkinos, C. M., Antoniadou, N., and Markos, A. (2014). Cyber-bullying: an investigation of the psychological profile of university student participants. J. Appl. Dev. Psychol. 35, 204-214. doi: 10.1016/j.appdev.2014.04.001

Kumpulainen, K., and Räsänen, E. (2000). Children involved in bullying at elementary school age: their psychiatric symptoms and deviance in adolescence. An epidemiological sample. Child Abuse Reject 24, 1567-1577. doi: 10.1016/ s0145-2134(00)00210-6
Kumpulainen, K., Räsänen, E., and Puura, K. (2001). Psychiatric disorders and the use of mental health services among children involved in bullying. Aggress. Behav. 27, 102-110. doi: 10.1002/ab.3

Li, Q. (2006). Cyberbullying in schools: a research of gender differences. Sch. Psychol. Int. 27, 157-170. doi: 10.1177/0143034306064547

Li, Q. (2008). A cross-cultural comparison of adolescents experience related to Cyberbullying. Educ. Res. 50, 223-234. doi: 10.1080/0013188080230 9333

MacDonald, C. D., and Roberts-Pittman, B. (2010). Cyberbullying among college students: prevalence and demographic difference. Procedia Soc. Behav. Sci. 9, 2003-2009. doi: 10.1016/j.sbspro.2010.12.436

Mason, K. L. (2008). Cyberbullying: a preliminary assessment for school personnel. Psychol. Sch. 45, 323-348. doi: 10.1002/pits.20301

Menesini, E., Modena, M., and Tani, F. (2009). Bullying and victimization in adolescence: concurrent and stable roles and psychological health symptoms. J. Genet. Psychol. 170, 115-133. doi: 10.3200/GNTP.170.2.11 5-134

Misawa, M. (2010). Racist and homophobic bullying in adulthood: narratives from gay men of color in higher education. New Horizons Adult Educ. Hum. Resour. Dev. 24, 7-23. doi: 10.1002/nha3.10370

Misawa, M. (2011). "The intersection of racist and homophobic bullying in adult and higher education," in Proceedings of the 30th Annual Midwest Research-toPractice Conference in Adult, Continuing, Community and Extension Education, (St. Louis, MO: Lindenwood University), 1-6.

Ortega, R., Calmaestra, J., and Mora, J. (2008). Cyberbullying. Int. J. Psychol. Psychol. Ther. 8, 183-192.

Sandín, B., Valiente, R. M., Chorot, P., Santed, M. A., and Lostao, L. (2008). SA45: forma abreviada del SCL-90 [SA-45: a brief form of SCL-90]. Psicothema 20, 290-296.

Schenk, A. M., and Fremouw, W. J. (2012). Prevalence, psychological impact, and coping of cyberbully victims among college students. J. Sch. Violence 11, 21-37. doi: 10.1080/15388220.2011.630310

Schenk, A. M., Fremouw, W. J., and Keelan, C. M. (2013). Characteristics of college cyberbullies. Comput. Hum. Behav. 29, 2320-2327. doi: 10.1016/j.chb.2013. 05.013

Selkie, E. M., Kota, R., Chan, Y.-F., and Moreno, M. (2015). Cyberbullying, depression, and problem alcohol use in female college students: a multisite study. Cyberpsychol. Behav. Soc. Netw. 18, 79-86. doi: 10.1089/cyber.2014.0371

Slonje, R., and Smith, P. K. (2008). Cyberbullying: another main type of bullying? Scand. J. Psychol. 49, 147-154. doi: 10.1111/j.1467-9450.2007.00 611.x

Smith, P. K., Mahdavi, J., Carvalho, C., Fisher, S., Russell, S., and Tippett, N. (2008). Cyberbullying: its nature and impact in secondary school pupils. J. Child Psychol. Psychiatry 49, 376-385. doi: 10.1111/j.1469-7610.2007.01 846.x

Smith, P. K., Mahdavi, J., Carvalho, C., and Tippett, N. (2006). An Investigation into Cyberbullying, its Forms, Awareness and Impact, and the Relationship Between Age and Gender in Cyberbullying. London: Anti-Bullying Alliance.

Soldberg, M. E., and Olweus, D. (2003). Prevalence estimation of school bullying with the olweus bully/victim questionnaire. Aggress. Behav. 29, 239-268. doi: 10.1002/ab.10047

Tokunaga, R. S. (2010). Following you home from school: a critical review and synthesis of research on cyberbullying victimization. Comput. Hum. Behav. 26, 277-287. doi: 10.1016/j.chb.2009.11.014

Turan, N., Polat, O., Karapirli, M., Uysal, C., and Turan, S. G. (2011). The new violence type of the era: cyber bullying among university students. Violence among university students. Neurol. Psychiatry Brain Res. 17, 21-26. doi: 10. 1016/j.npbr.2011.02.005

van der Kolk, B. A. (2005). Developmental trauma disorder: a new, rational diagnosis for children with complex trauma histories. Psychiatr. Ann. 35, 401-408. doi: 10.3928/00485713-20050501-06

van Geel, M., Vedder, P., and Tanilon, J. (2014). Relationship between peer victimization, cyberbullying, and suicide in children and adolescents: a Metaanalysis. JAMA Pediatr. 168, 435-442. doi: 10.1001/jamapediatrics.2013.4143

Walker, C. M., Sockman, B. R., and Koehn, S. (2011). An exploratory study of cyberbullying with undergraduate university students. TechTrends 55, 31-38. doi: $10.1007 /$ s11528-011-0481-0 
Washington, E. T. (2014). An overview of cyberbullying in higher education. Adult Learn. 26, 21-27. doi: 10.1177/1045159514558412

Willard, N. E. (2006). Cyberbullying and Cyberthreats: Responding to the Challenge of Online Social Cruelty, Threats, and Distress. Eugene, OR: Center for Safe and Responsible Internet Use.

Wolak, J., and Finkelhor, D. (2006). Examining characteristics and associated distress related to internet harassment: findings from the second youth internet safety survey. Pediatrics 118, 1169-1177.

Ybarra, M. L., and Mitchell, K. J. (2004). Online aggressor/targets, aggressors, and targets: a comparison of associated youth characteristics. J. Child Psychol. Psychiatry 45, 1308-1316. doi: 10.1111/j.1469-7610.2004.00328.x
Conflict of Interest Statement: The authors declare that the research was conducted in the absence of any commercial or financial relationships that could be construed as a potential conflict of interest.

Copyright (c) 2019 Felipe-Castaño, León-del-Barco, Polo-del-Río, Mendo-Lázaro, Gómez-Carroza and Fajardo-Bullón. This is an open-access article distributed under the terms of the Creative Commons Attribution License (CC BY). The use, distribution or reproduction in other forums is permitted, provided the original author(s) and the copyright owner(s) are credited and that the original publication in this journal is cited, in accordance with accepted academic practice. No use, distribution or reproduction is permitted which does not comply with these terms. 